\title{
RASGRF1 in CRF cells controls the early adolescent female response to repeated stress
}

\author{
Shan-xue Jin ${ }^{1, *}$, David A Dickson ${ }^{1,2, *}$, Jamie Maguire ${ }^{2,3}$ and Larry A Feig ${ }^{1,2}$ \\ 1Department of Developmental, Molecular, and Chemical Biology, Boston, Massachusetts, USA \\ ${ }^{2}$ Neuroscence Program, Graduate School of Biomedical Sciences, Tufts University School of Medicine, Boston, Massachusetts, USA \\ ${ }^{3}$ Department of Neuroscience, Tufts University School of Medicine, Boston, Massachusetts, USA \\ Correspondence should be addressed to L A Feig: larry.feig@tufts.edu \\ *(S Jin and D A Dickson contributed equally to this work)
}

\begin{abstract}
RASGRF1 (GRF1) is a calcium-stimulated guanine-nucleotide exchange factor that activates RAS and RAC GTPases. In hippocampus neurons, it mediates the action of NMDA and calcium-permeable AMPA glutamate receptors on specific forms of synaptic plasticity, learning, and memory in both male and female mice. Recently, we showed GRF1 also regulates the HPA axis response to restraint stress, but only in female mice before puberty. In particular, we found that after 7 days of restraint stress (7DRS) (30 $\mathrm{min} /$ day) both elevated serum CORT levels and induction of an anxiolytic phenotype normally observed in early adolescent (EA) female mice are blocked in GRF1-knockout mice. In contrast, no effects were observed in EA male or adult females. Here, we show this phenotype is due, at least in part, to GRF1 loss in CRF cells of the paraventricular nucleus of the hypothalamus, as GRF1 knockout specifically in these cells suppressed 7DRS-induced elevation of serum CORT levels specifically in EA females, but only down to levels found in comparably stressed EA males. Nevertheless, it still completely blocked the 7DRS-induced anxiolytic phenotype observed in EA females. Interestingly, loss of GRF1 in CRF cells had no effect after only three restraint stress exposures, implying a role for GRF1 in 7DRS stress-induced plasticity of CRF cells that appears to be specific to EA female mice. Overall, these findings indicate that GRF1 in CRF cells makes a key contribution to the distinct response EA females display to repeated stress.
\end{abstract}

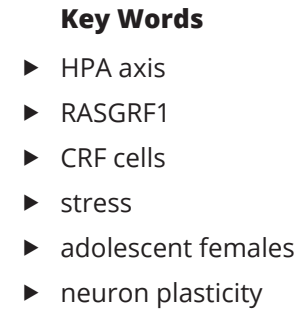

Journal of Endocrinology (2020) 245, 397-410

\section{Introduction}

The body's reaction to environmental stressors involves sequential hormone release in the hypothalamuspituitary-adrenal (HPA) axis (McEwen 2007). These perturbations stimulate cortisone (corticosterone in rodents) (CORT) release from the adrenal cortex to mobilize an integrated protective response to stress. The first HPA axis response is the release of corticotropinreleasing factor/hormone (CRF/CRH) from the terminals of parvocellular CRF hypothalamic neurons in the paraventricular nucleus (PVN) into hypophyseal portal vessels. Adrenocorticotropic hormone (ACTH) is then released from the pituitary, which stimulates corticosteroid synthesis and release from the adrenal gland.

Clear sex- and age-dependent differences in both how the HPA axis responds to stress, and how stress leads to psychiatric disorders have been documented (Bale \& Epperson 2015). A consistent trend in animals demonstrates higher and longer-lasting CORT secretion 
after various stressors in adult females compared to males (Heck \& Handa 2019). Sex differences at multiple sites in the HPA axis have been implicated, including excitation of CRF cells in the PVN, CRF expression in them, pituitary production of ACTH, and glucocorticoid feedback on the PVN (Bale \& Epperson 2015, Heck \& Handa 2019). Moreover, women are roughly twice as likely as men to suffer from stress-associated disorders such as anxiety, PTSD, and depression (Bangasser \& Valentino 2014).

Age-dependent differences in the response to stress have also been found. Adolescence is between $\sim 10$ and 25 years in humans and postnatal days $28-55$ in rodents (Burke \& Miczek 2014, Doremus-Fitzwater \& Spear 2016). It can be divided into early, mid and late stages, with puberty beginning at mid-adolescence (Burke \& Miczek 2014). Adolescence is a time of continuing brain maturation, particularly in regions that control the HPA axis (Juraska \& Willing 2017). Excess stress during this crucial developmental stage may influence brain maturation and contribute to both anxiety and depression during adolescence, and psychiatric disorders later in life (Spear 2000). Consistent with this finding, many studies show that animals at various stages of adolescence respond differently to stress than adults. In general, it has been noted that exposure to a variety of stressors lead to greater or more prolonged hormonal responses in adolescents compared to adults (Romeo 2018). For example, prepubertal, early adolescent (EA) (25-30 days of age) male and female rats exposed to an acute stressor display a significantly extended hormonal response relative to adults ( $>65$ days of age) (Romeo et al. 2006). Moreover, after exposure to a combination of stressors, adolescent rats display reduced anxiety, rather than the enhanced anxiety typically seen in adults, that is associated with enhanced risk taking (Toledo-Rodriguez \& Sandi 2011). In humans, the risk of depression reaches its maximum around early adolescence and decreases as humans age through mid and late-adolescence (McLaughlin \& King 2015).

Sex differences in the stress response among adolescents have also been observed. For example, restraint stress significantly increased alcohol intake and preference in female adolescent rats, but decreased alcohol intake and preference in male adolescent and female adult rats (Wille-Bille et al. 2017). Early adolescent (EA)-specific differences between girls and boys have also been observed. For example, young girls exhibit greater CORT stress reactivity to social stress tests than boys (Blumenthal et al. 2009, Gunnar et al. 2009, Blumenthal et al. 2014, McLaughlin \& King 2015). Moreover, EA girls are more prone than EA boys to anxiety, depression and eating disorders, as well as suicidal ideation, while EA boys are more susceptible to ADHD (Hankin et al. 1998, Skogli et al. 2013).

PVN neurons that release CRF are tightly regulated in many ways. For example, with repeated exposure to stress, they display cellular, synaptic, and connectional plasticity that serves to maximize the ability of the HPA axis to maintain response flexibility (Aguilera \& Liu 2012). At the cellular level, chronic stress often enhances the production of CRF and its co-secretagogue arginine vasopressin (AVP) and alters neurotransmitter receptor expression, so as to maximize cellular excitability. Interestingly, differences in the CRF cell response to stress have been found between male and female EA mice, such that social isolation, but not acute stress, alters the intrinsic properties of these cells in a sexually dimorphic fashion (Senst et al. 2016).

p-140 RASGRF1 (GRF1) and p-130 RASGRF2 (GRF2) constitute a family of calmodulin-binding, calciumactivated exchange factors for both Ras and Rac GTPases that are expressed in neurons (not glia) throughout the adult CNS at similar levels in both males and females (Feig 2011). They have very similar domains including calmodulin (CaM)-binding IQ motifs, as well as Ras-activating CDC25 domains and Rac-activating DH domains, but regulate different forms of synaptic plasticity, learning and memory. We showed that GRF1 mediates LTD in CA1 hippocampus neurons induced by NR2B-type NMDA receptors through Rac/p38 Map kinase signaling (Li et al. 2006). Moreover, when mice reach 2 months of age they acquire the ability perform the learning paradigm of contextual discrimination that requires the appearance of high-frequency stimulated (HFS) LTP in the CA1 hippocampus that is mediated by a newly functional calcium-permeable AMPA receptor (CP-AMPAR)/GRF1/Rac GTPase/p38 map kinase signaling cascade (Jin et al. 2013). GRF1 can also mediate Erk map kinase by dopamine receptors in the striatum (Cerovic et al. 2015) and by NR2B-type NMDA receptors in cultures of cortical neurons (Krapivinsky et al. 2003).

Recently, we showed using knockout mice that GRF1 also contributes to regulation of the HPA axis in mice, but unlike its roles described above, it does so in a sex, age, and stimulus-dependent manner (Uzturk et al. 2015). In particular, GRF1 contributes to the negative feedback the hippocampus plays in regulating the HPA axis response to up to five exposures of restraint stress (30 $\mathrm{min} /$ day) in prepuberal early-adolescent (EA) (pn-d28-35) females. As such, EA female GRF1-knockout mice, but not their EA male, late adolescent or adult female counterparts display 
an exaggerated serum CORT response. However, after seven exposures to restraint stress, GRF1 plays a positive, rather than negative, role specifically in EA females, such that elevated serum CORT normally observed is blocked in only in EA female GRF1-knockout mice. GRF1 also contributes to the anxiolytic behavior we observed in EA female mice after repeated restraint stress (Uzturk et al. 2015). Finally, puberty-associated hormonal changes do not contribute to this phenotype because the effects are observed before puberty and ovariectomy had no effect on GRF1-knockout phenotypes after puberty.

Here, by suppressing GRF1 function only in CRF cells in the PVN of the hypothalamus, we found qualitatively similar results. Serum CORT response to seven exposures of restraint stress (30 $\mathrm{min} /$ day) (7DRS) was suppressed only in EA females, but only partially, to levels found normally in similarly stressed control males. Nevertheless, it was sufficient to completely block induced anxiolytic phenotype normally observed in EA female mice. In addition, GRF1 in CRF cells of EA females did not influence the HPA response to fewer exposures to restraint stress, implicating GRF1 in a form of CRF cell neuroplasticity likely unique to this cell type.

\section{Materials and methods}

\section{Animals care facilities}

All mice included in this study were housed in temperature, humidity, and light-controlled $(14 \mathrm{~h}$ on/10 h off LD cycle) rooms in a fully staffed dedicated animal core facility led by on-call veterinarians at all hours. Food and water were provided ad libitum. All procedures and protocols involving these mice were conducted in accordance with and approved by the Institutional Animal Care and Use Committee of the Tufts University School of Medicine, Boston, MA, USA. CRF-ires-CRE mice were obtained from Dong Kong, Tufts University School of Medicine via Jackson Labs (stock no.: 012704) and bred in-house in a C57Bl/6 background (https://www.jax.org/ strain/012704).

\section{Statistical methods}

All statistical analyses were performed in GraphPad Prism v.8.3.1. All grouped analyses comparing CORT measurements with/without stress, with GFP or CRE injection, and including EA male, EA female, and adult female mice were analyzed using a three-way ANOVA (main effects: age/sex (three-level factor: EA male,
EA female, and adult female), 7DS, CRE), and F-statistics and $P$ values are reported in the text for all significant main effects and all interactions. For analysis of the knockdown of GRF1 mRNA in adeno-CRE injected floxed animals, as well as the CRF-Cre injected EA female mice after 3DS, analysis was carried out using a two-way ANOVA (factors: Cre, 3DS) in the same fashion as described above. For time course studies, analyses were carried out using mixed effect models for each age/sex of mouse individually, as each time point was gathered from a distinct cohort of mice. Post hoc analyses comparing CORT measurements in the 7DS or 3DS condition between GFP and CRE injected animals were corrected for multiple comparisons using Sidak's method, in the case of two-way ANOVAs to assess differences in CORT following 7DS or 3DS within groups, for the EPM analysis, and for mixed effect models comparing CORT levels at different time points. Tukey's method was used in the case of three-way ANOVAs where all means are compared to all other group means. All post hoc analyses were reported with the t-statistic and the multiplicity adjusted $P$ value. For all analyses, a $P<0.05$ was considered significant.

\section{Viruses}

AAV-CRE as obtained from Virovek; lenti-CRF-CRE was obtained from the Virology Core of Emory University; CRE-inducible L10a-GFP adenovirus was obtained from Eric Schmidt (Rockefeller University).

\section{Generation of floxed-GRF1 mice}

The conditional knockout of GRF1 was accomplished by conditional deletion of a $96 \mathrm{bp}$ coding region in the DH domain in exon 6, and the insertion of loxP sites flanking exon 6 . The FRT-flanked selection cassette was removed in vivo by crossing with recombinase deleter mice. Recombinant mice were back-crossed six times into the $\mathrm{C} 57 \mathrm{Bl} / 6$ background.

\section{RNA extraction}

For RNA extractions from whole PVN, total RNA was isolated using the Single Cell RNA Purification Kit from Norgen Biotek (Thorold, ON, Canada) according to the manufacturers protocol. All RNA isolates were assessed for concentration and purity using a Nanodrop 2000c Spectrophotometer (ThermoFisher Scientific) and/or an Agilent 2100 Bioanalyzer. 


\section{Real-time qPCR}

Relative gene expression for all samples was determined using the iScript cDNA synthesis kit, and SYBR Green MasterMix purchased from ThermoFisher Scientific. $75 \mathrm{ng}$ of total RNA from whole PVN extractions were used in the initial cDNA synthesis step. Real-time PCR was performed for each target and sample in triplicate on a StepOnePlus PCR System (Applied Biosystems). All data were analyzed using the comparative $\Delta \Delta \mathrm{CT}$ method to generate relative expression data using rps29 as the internal loading control. Primers used: rps29 Fwd: 5'-GTCTGATCCGCAAATACGGG-3', rps29 Rev: 5'-AGCCTATGTCCTTCGCGTACT-3'; rasgrf1 Fwd: 5'-ATC ACCTCCTCCATCAACCG-3', rasgrf1 Rev: 5'-CTGCCA TCTGATGACACAAGC-3', CRF Fwd: 5'-GGCATCCTG AGAGAAGTCCCTC-3', CRF Rev: 5'-ACAGAGCCA CCAGCAGCATG-3'.

\section{Translating ribosome affinity purification}

Ribosome-bound RNA isolation was carried out with an optimized form of the TRAP protocol (Nectow et al. 2017). Briefly, we began by covalently binding antiGFP antibodies (19C8, 19F7, a gift from Eric Schmitt, Rockefeller University) to magnetic Dynabeads (Invitrogen), and treating with IgG-free BSA to reduce background binding. Whole PVNs were homogenized using plastic pestles, spun down to remove cellular debris, and added to the anti-GFP beads for binding for $2 \mathrm{~h}$ at $4^{\circ} \mathrm{C}$. The unbound fraction for each sample was removed and kept on ice for later RNA extraction. The beads were then washed twice with a low strength $\mathrm{KCl}$ buffer, and three times with a high strength $\mathrm{KCl}$ buffer. RNA was then extracted from both the washed beads and the unbound fractions using the Single Cell RNA purification kit (Norgen), with slight modifications to improve yield. For the bead samples, $100 \mu \mathrm{L}$ of lysis buffer was added to the beads before vortexing five times for $5 \mathrm{~s}$ each, and letting rest at room temperature for at least $5 \mathrm{~min}$. The beads were removed by magnet, and the extraction then proceeded normally. For the unbound samples, 1 volume (the total amount of unbound sample, typically $\sim 150 \mu \mathrm{L}$ ) of lysis buffer was added, the sample was vortexed, and then two volumes of room temperature 70\% EtOH were added before proceeding with the extraction normally. All samples were eluted in $20 \mu \mathrm{L}$ of DEPC-treated $\mathrm{H}_{2} \mathrm{O}$ before quantification and quality assessment as described in the RNA extraction section above.

\section{Immunohistochemistry}

Fourteen days after the stereotactic surgeries, mice were deeply anesthetized with ketamine/xylazine and transcardially perfused with $0.1 \mathrm{M}$ phosphate buffered saline (PBS) followed by 4\% paraformaldehyde (PFA 4\%) dissolved in PB $0.1 \mathrm{M}$. Brains were extracted and postfixed in PFA 4\% for $24 \mathrm{~h}$. Brains were transferred to $30 \%$ sucrose for $48-72 \mathrm{~h}$ before slicing $30 \mu \mathrm{m}$ coronal sections through the extent of the PVN using a cryostat. Sections were stored in cryoprotectant at $-20^{\circ} \mathrm{C}$ until use. Each immunohistochemical analysis was conducted from $30 \mu \mathrm{m}$ sections spanning the PVN.

Free-floating sections were rinsed extensively in PBS with $0.3 \%$ Triton X-100 (PBS-T). Sections were blocked for $1 \mathrm{~h}$ at room temperature in PBS-T with 5\% normal goat serum. Primary antibody, antiGRF1 (C 18) (Santa Cruz Biotechnology), was diluted in the blocking solution (1:200), incubated overnight at $4^{\circ} \mathrm{C}$, and rinsed three times for $15 \mathrm{~min}$ in PBS-T. The sections were then incubated for $1.5 \mathrm{~h}$ at RT with a Alexa 488 or Cy3-conjugated secondary antibody (1:300; Invitrogen). The stained sections were examined with a confocal microscope and images were captured with a CCD spot camera. Images were then analyzed using ImageJ. For CRF cell-specific GRF1 expression, CRF cells were first identified by their robust GFP expression throughout the cytoplasm, and were individually traced with an overlay (10-20 GFP+ cells per slice, at least three slices per animal). The overlay was then added to the GRF1 channel of the image to quantify the total fluorescence signal for GRF1 inside each of the outlined cells, calculated as corrected total cell fluorescence ((total fluorescence of the cell) - ((area of the cell) $\times$ background signal)) using the average of three background measurements for each image. Cells were said to be positive for GRF1 if the total fluorescence counted for the cell was at least double that of the background staining, given that GRF1 is robustly expressed in many cell types in the brain.

\section{Stereotactic injections}

Twenty-one or 22-day-old mice were injected as previously described (Darcy et al. 2014); however, coordinates for hypothalamic PVN injection were $0.8 \mathrm{~mm}$ posterior to Bregma, $0.2 \mathrm{~mm}$ lateral from the midline, $5.18 \mathrm{~mm}$ beneath the surface of the skull. Each injection consisted of $1 \mu \mathrm{L}$ of adenovirus or lentivirus infused at a rate of $0.06 \mathrm{~mL} / \mathrm{min}$. An infusion pump controlling the plunger on the Hamilton syringe precisely regulated the rate of injection. The needle was then left in place for $8 \mathrm{~min}$ 
prior to withdrawal from the brain. 4-7 mice were used for each experiment. Half of floxed siblings were injected with CRE-expressing virus for experimental samples and half with GFP-expressing virus as controls.

\section{Restraint stress}

Restraint stress experiment were carried out as previously described (Uzturk et al. 2015). Briefly, mice were placed into custom-fit cone-shaped plastic bags and secured in place for 30 min every day. The cone has an open end so the mouse can breathe, but can otherwise not move for the duration of the stressor. Mice are always stressed between 12:00 $\mathrm{h}$ and 14:00 $\mathrm{h}$ to control for the circadian fluctuations of corticosterone production.

\section{Corticosterone (CORT) ELISA}

CORT measurements were carried out as previously described using the Corticosterone ELISA Kit from Enzo Life Sciences (Farmingdale, NY, USA) (Uzturk et al. 2015). We noticed that the EA female mice used here (floxed-BL6 mice) display a greater CORT response that we found in Bl6 mice 3 years ago, which could be caused by different housing conditions over the years or a difference in the strain.

\section{Elevated plus maze}

Mice were placed in the center of a plus-shaped maze elevated $40 \mathrm{~cm}$ from the ground, composed of two open and two closed arms, each $35.5 \mathrm{~cm}$ long and $5 \mathrm{~cm}$ wide (Campden Instruments, Lafayette, IN, USA). General mouse activity was analyzed for $5 \mathrm{~min}$ and the percent time spent in the open arms was recorded using Motor Monitor Software (Campden Instruments).

\section{Results}

Inhibition of GRF1 expression in the PVN of the hypothalamus suppresses elevation of serum corticosterone levels induced by 7 days ( $30 \mathrm{~min} /$ day) of restraint stress (7DRS) specifically in early-adolescent (EA) female mice

We demonstrated previously that GRF1 negatively regulates the HPA axis response to short-term restraint stress (1-5 days; $30 \mathrm{~min} /$ day) in early-adolescent (EA) (prepubescent (periadolescent)) females (pn days 28-35) (Uzturk et al. 2015).
In particular, GRF1-knockout mice display an exaggerated enhancement of serum corticosterone (CORT) levels after these exposures. No effect was detected in EA male, late adolescent (pn-days 35-42) female or adult female mice. This effect was found to be due to GRF1 in the CA1 hippocampus, consistent with the negative feedback role this brain region plays on the HPA axis.

However, we also showed that GRF1 plays the opposite role after 7 days of the same restraint stress (7DRS), again specifically in EA females, where loss of GRF1 leads to a complete blockade of elevated serum CORT response. We hypothesized that this difference is due to GRF1 function in a different brain area that plays a positive role in promoting the HPA axis to repeated stress. Thus, we first investigated the paraventricular nucleus (PVN) of the hypothalamus, because this region is known for this function and previous single-cell RNAseq studies found that GRF1 is expressed in many cell types cells throughout the PVN, at least in adult males (Romanov et al. 2017) (also see http://linnarssonlab.org/hypothalamus/). We expanded this finding, using GRF1-specific antibodies, as we detected positive staining of cells throughout the PVN of wild-type EA female mice compared to results using GRF1-knockout mice (Fig. 1A and B).

Therefore, we tested whether GRF1 in the PVN hypothalamus contributes to stress-induced CORT production after repeated (7) daily episodes of restraint stress (30 min/day) (7DRS) in EA mice. To this end, the expression of GRF1 was inhibited in the PVN using stereotactic injection of adenovirus expressing CRE recombinase, or GFP as controls, into this brain region of 21-22-day-old female floxed GRF1 mice (Fig. 1C and D). After waiting 7 days to allow virus expression, mice were exposed to 7DRS, or control handling, and then CORT levels in serum were measured. This timeline was employed so that at the end of the experiment mice were still in early adolescence, because we showed that after this developmental stage, GRF1 no longer plays a role in HPA axis regulation (Uzturk et al. 2015). As expected, qPCR analysis of whole PVN RNA shows that injection of adenoCRE severely inhibited GRF1 mRNA levels compared to GFP controls in both EA females and males (Fig. 2A). Two-way ANOVA (factors: CRE, sex) revealed a significant effect for injection of adeno-CRE $\left(\mathrm{F}_{(1,8)}=428.3, P<0.0001\right)$ without a significant interaction between these terms $\left(\mathrm{F}_{(1,8)}=0.2942, P=0.6023\right)$; Sidak post hoc tests revealed a significant difference in GRF1 expression after injection of adeno-CRE in both females $(\mathrm{t}=15.70, P<0.0001)$ and males $(\mathrm{t}=13.85, P<0.0001)$ when compared to their adeno-GFP-injected counterparts. 
A

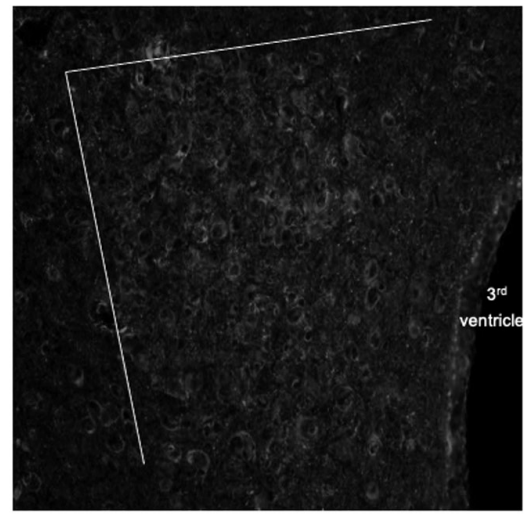

C

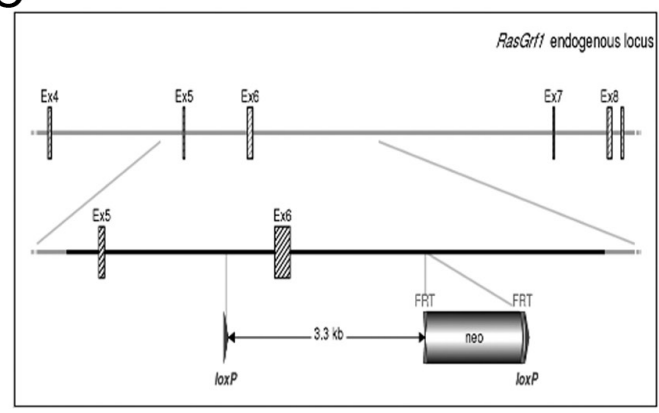

B

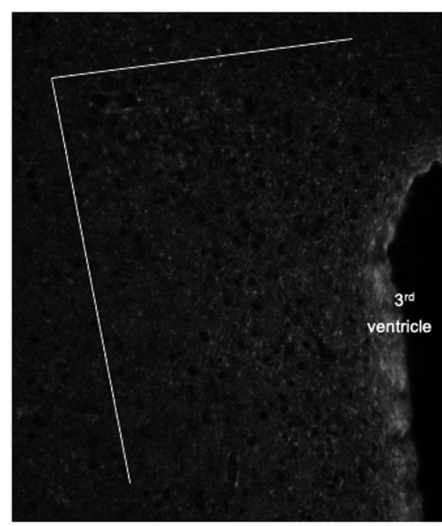

D

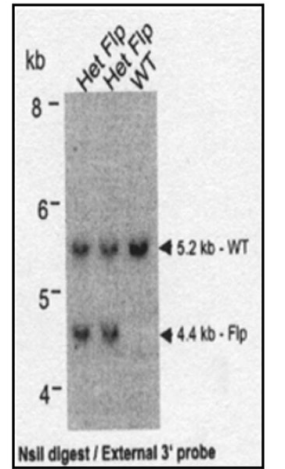

Figure 1

Generation of conditional GR1-knockout mice. (A and B) GRF1 protein expression in the PVN of brain slices from WT mice (A) and whole animal GRF1\% knockout mice (B) stained with antiRASGRF1 antibody (scale bar, $50 \mu \mathrm{m}$ ). White lines represent the borders of the PVN region. Third ventricle can be visualized in the bottom right of both panels as labeled. (C) Schematic representation of targeting strategy selected. Hatched rectangles represent RASGRF1 coding sequences, grey rectangles indicate non-coding exon portions, solid lines represent chromosome sequences. The neomycin-positive selection cassette is indicated. loxP sites are represented by blue triangles and FRT sites by double red triangles. The size of the flanked RASGRF1 sequence to be deleted is specified. (D) Genomic blots identifying heterozygous conditional knockout mice. Primer sequences available upon request.
After injection, we observed qualitatively similar results as those we obtained after exposing animalwide GRF1-knockout mice to 7DRS, but quantitative differences were also observed. In particular, as in whole animal GRF1 knockouts, baseline circulating CORT levels in EA unstressed animals were similar between adenoGFP and adeno-CRE-injected mice, (Uzturk et al. 2015) (Fig. 2B, C and D). But now we detect higher serum CORT response in EA females than we did then, such that their response is greater than that observed in similarly stressed EA males. One possibility for this discrepancy is that a male investigator is involved now while a female was during those experiments (Sorge et al. 2014), and a floxed B16 strain of mouse is now being used. Also, the animal facility environmental likely changed over the years between experiments.

Moreover, while inhibition of serum CORT rise by 7DRS in whole animal GRF1-knockout mice was complete, now blocking GRF1 only in the PVN led to partial suppression after the final $30 \mathrm{~min}$ exposure to 7DRS. CORT levels were significantly reduced ( 50\%) in EA female mice with suppressed GRF1 expression when compared to their adeno-GFP-injected counterparts (Fig. 2B). Three-way ANOVA (factors: sex/age, CRE, 7DS) revealed a significant effect for sex/age $\left(\mathrm{F}_{(2,52)}=30.06\right.$,
$P<0.0001)$ and 7DS $\left(\mathrm{F}_{(1,52)}=488.7, P<0.0001\right)$, as well as the interaction between these two factors $\left(\mathrm{F}_{(2,52)}=25.25\right.$, $P<0.0001)$, the interaction between sex/age and adenoCRE injection $\left(\mathrm{F}_{(2,52)}=14.49, \quad P<0.0001\right)$, and the interaction of all three factors $\left(\mathrm{F}_{(2,52)}=14.31, P<0.0001\right)$, without a significant interaction for the adeno-CRE injection and 7DS factors $\left(\mathrm{F}_{(1,52)}=0.0908, P=0.7644\right)$; Tukey's multiple comparisons post hoc tests revealed a significant decrease in CORT levels after 7DS between adeno-GFP and adeno-CRE injected early-adolescent females $(\mathrm{q}=8.947, P<0.0001)$.

Interestingly, GRF1 knockdown reduced serum CORT levels in EA females to those similar to that found in control stressed EA male mice (see Fig. 2C bars on left), suggesting that for stressors experienced in these experiments GRF1 function is needed for to the enhanced response EA female mice display over EA males.

Importantly, GRF1 knockout did not affect stressinduced CORT levels in EA male mice (Fig. 2C, bars on right). In addition, GRF1 knockout did not suppress CORT level elevation in adult female mice (Fig. 2D). These findings are consistent with our previous work using global GRF1-knockout mice (Uzturk et al. 2015).

GRF1 knockout actually led to a small increase in stress-induced CORT levels in adult females 
A
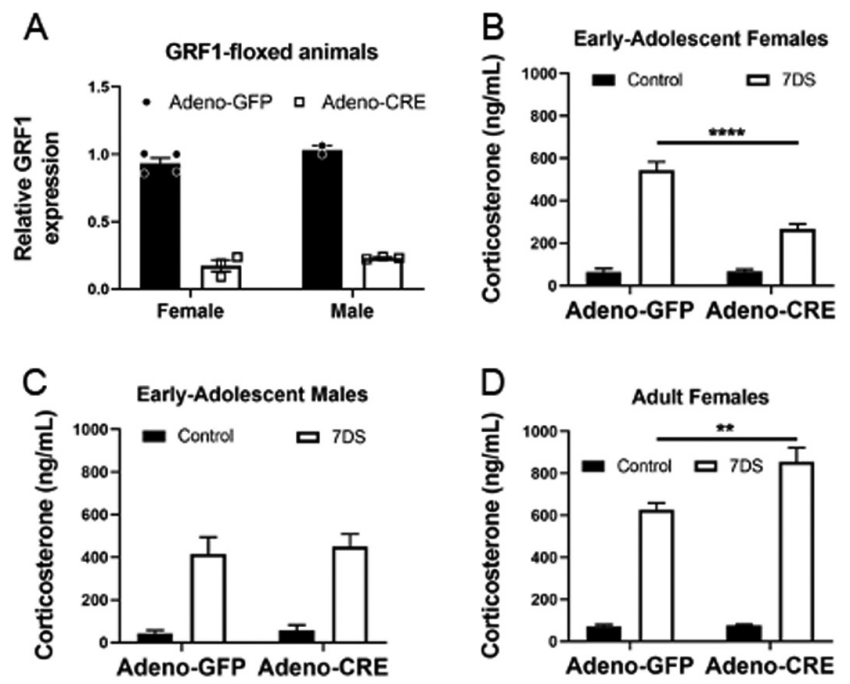

Figure 2

Inhibition of GRF1 function in the PVN of early adolescent (EA) female mice, but not in their male counterparts or adult female mice, suppresses HPA axis response to repeated restraint stress. (A) Injection of adeno-CRE virus into the PVN of floxed EA females (left) and floxed EA males (right) effectively inhibits expression of GRF1 mRNA when compared to floxed animals injected with adeno-GFP as control. Each symbol represents an individual animal. (B) Suppression of GRF1 expression in the PVN of EA females partially blocks elevated serum corticosterone in response to seven exposures of restraint stress ( $30 \mathrm{~min} /$ day). Serum corticosterone levels measured after stereotactic injection of either adeno-GFP or adeno-CRE into the PVN of floxed GRF1 mice followed by control handling or 7DS ( $n=7$ mice/group). (C) The same as in (B), but for EA male mice ( $n=4$ in each group) or (D). Adult female mice ( $n=5$ mice/group). Data presented as the mean +/- S.E.M. Analyses used: (A) two-way ANOVA, (B, C and D) three-way ANOVA. ** $P<0.01, * \star \star \star * P<0.0001$.

(Tukey's multiple comparisons post hoc tests revealed a significant increase in CORT levels after 7DS between adeno-GFP and adeno-CRE-injected adult females $(\mathrm{q}=6.210, P=0.0029)$ (Fig. 2D)). This raised the possibility of an indirect opposite effect of GRF1 knockout in the other GRF1 expressing cell types in the PVN of adult females that express GRF1 (Fig. 1A), as we do not observe the same effect when we knockout GRF1 only in CRF cells (see below).

\section{Inhibition of GRF1 expression only in PVN CRF cells suppresses elevation of serum corticosterone levels induced by 7 days ( $30 \mathrm{~min} /$ day) of restraint stress (7DRS) specifically in early-adolescent (EA) female mice}

Next, we investigated whether the suppression of elevated serum CORT levels in mice where GRF1 is knocked down only in the PVN after 7DRS (Fig. 1) is due, at least in part, to the loss of GRF1 in PVN CRF cells. Previous single cell RNAseq analysis demonstrated robust GRF1 expression in adult male PVN cells co-expressing CRF (Romanov et al. 2017) (also see http://linnarssonlab.org/hypothalamus/). First, we tested whether GRF1 is also expressed at the mRNA level in PVN CRF cells in EA females. To this end, GRF1 mRNA was quantified in brain slices from mice where only CRF cells express GFP. To tag CRF cells this way, the PVN of 21-day-old transgenic mice expressing CRE recombinase only in CRF cells (CRF-ires-CRE) (Taniguchi et al. 2011) were injected with adeno-associated virus encoding a CRE-on construct that expresses GFP targeted to the cytoplasm by virtue of fusing it to the ribosomal protein L10a (see the Materials and methods section and Nectow et al. 2017), where GRF1 is expressed. Male and female EA as well as adult female mice were then exposed to 7 days of stress, when the sex- and age-dependent role for GRF1 is apparent. (Uzturk et al. 2015) (and see Fig. 1).

Because the L10a ribosomal subunit in GFP-L10 associates with actively transcribed mRNA, we could test whether EA female mice express GFP predominantly in CRF cells by quantifying CRF mRNA associated with GFP after its immunoprecipitation from cells, using the 'TRAP protocol' (Nectow et al. 2017). As expected with successful immunoprecipitation, we found an enrichment of CRF mRNA of $\sim 7-20$ fold in precipitated mRNA compared to ubiquitously expressed rsp29 mRNA, in RNA extracted from the PVN from infected mice. Then, we compared the ratio of GRF1 to CRF mRNA in the precipitated vs unbound fractions from both male and female EA mice and found that GRF1 mRNA was clearly enriched in the precipitated population of both mRNAs, although not to the level of CRF (Fig. 3A).

The finding that GRF1 is enriched in mRNA from CRF cells compared to total PVN mRNA, but not the extent that CRF is (only $\sim 1 / 3$ the level) was also expected. This is because, unlike CRF, GRF1 is expressed throughout the PVN (Fig. 1). However, while GRF1 is expressed in excitatory neurons, it is not expressed in all cells such as glia, which make up a significant fraction of PVN cells (Stern \& Filosa 2013).

To confirm that GRF1 is expressed in EA female CRF cells at the protein level, brain slices containing the PVN were stained with GRF1 antibody and the level of both red (GRF1) and green (GFP) were visualized. These images show representative examples of cells co-stained with GRF1 and CRF in both EA female and EA male CRF cells (Fig. 3B and C), despite the fact that GRF1 is not needed in the PVN of the latter mouse population for their full HPA axis response to repeated restraint stress (Fig. 2).

Next, the consequence of inhibiting GRF1 only in CRF cells was investigated. A protocol similar to that described 
A

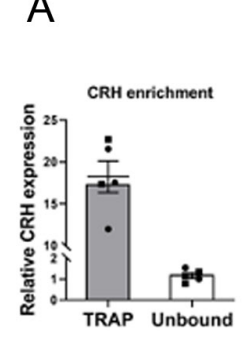

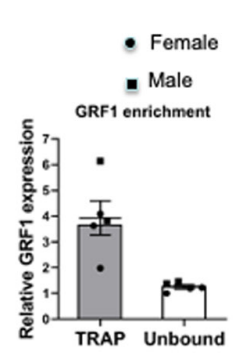

B Early-Adolescent Females

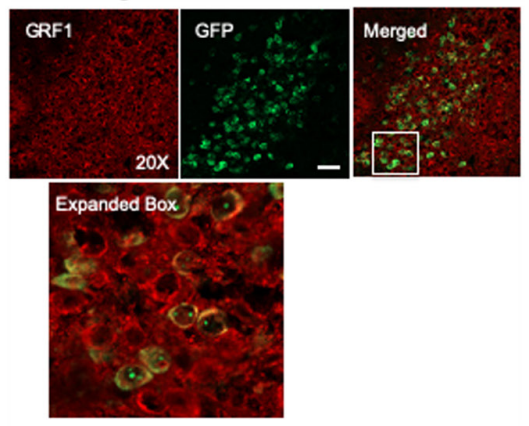

C Early-Adolescent Males

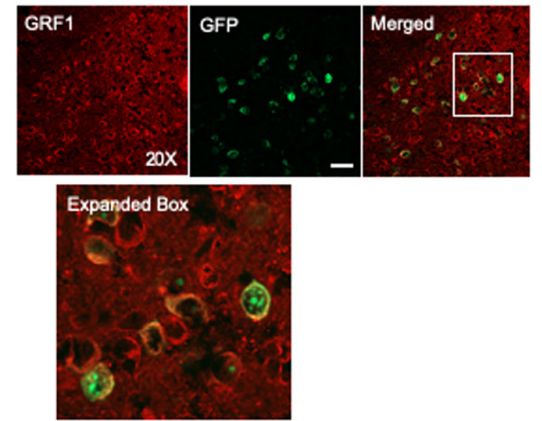

Figure 3

GRF1 is expressed in CRF cells of the PVN. The PVN of mice expressing CRE specifically in CRF cells were infected with a lentivirus expressing cytosoltargeted GFP-L10a fusion protein to allow isolation of ribosome-associated mRNAs specifically in CRF cells as well as specifically label CRF cells with GFP. (A) CRF cell mRNA was purified from total PVN mRNA by immunoprecipitation of GFP-L10a and compared with unbound non-selected mRNA for CRF (left) and GRF1 (right) mRNA levels detected by qPCR. Results from three EA females (circles) and two EA males (squares) are shown. Alternatively, brains sections were immunostained with anti-GRF1 antibody following 7DS for EA females (B), and EA males (C). The insert bars for each set of images shows the percentage of CRF cells (GFP+ cells) that also stained positively for GRF1 expression (scale bar, $50 \mu \mathrm{m}$ ). A full colour version of this figure is available at https://doi.org/10.1530/JOE-19-0375.

in Fig. 2 was employed, where GRF1 knockdown was targeted to the entire PVN of floxed GRF1 mice using a virus with a constitutive promoter driving CRE. However, here a lentivirus expressing CRE from a CRF cell-specific promoter (lenti-CRF-CRE (Melon et al. 2018)) was used in its place, or a virus expressing GFP as control. To confirm that this protocol actually reduced GRF1 levels specifically in CRF cells, wild-type or floxed GRF1 mice were co-injected with the CRF-CRE expressing lentivirus along with the GFP-L10 expressing virus used in Fig. 3 to identify CRF expressing cells. Then, GRF1 antibody staining in CRF cells was compared in virus injected

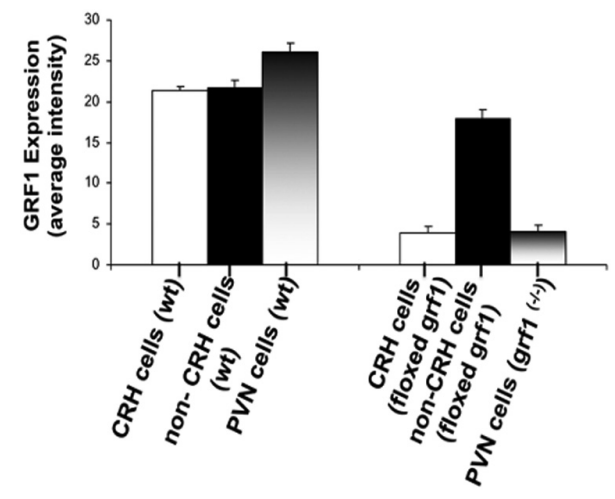

\section{Figure 4}

Demonstration of suppressed GRF1 expression specifically in $\mathrm{CRH}$ cells of the PVN. Levels of GRF1 protein expression in WT mice (left) in CRF cells (white bar), non-CRF expressing cells (black bar), or the average cell in the PVN (graded bar). The same expression was quantified in floxed mice (right) after injection of lentivirus expressing CRE recombinase under the control of the CRF promoter again looking in CRF cells (white bar) or non CRF expressing cells (black bar), compared to the average PVN cell in global GRF1 $\%$ animals (graded bar).

(C) 2020 Society for Endocrinology Published by Bioscientifica Ltd. Printed in Great Britain wild-type mice or floxed GRF1 mice. As expected, GRF1 staining in GFP-L10 expressing CRF cells was drastically reduced in virus-injected floxed GRF1 mice compared to wild-type mice (Fig. 4, white bars). This level of reduction was comparable to what is seen in GRF1 staining reductions observed in animal wide GRF1 knockout mice (Fig. 4, graded bars, also see Fig. 1A and B). Finally, GRF1 knockdown was specific for CRF cells because there was no reduction in GRF1 staining seen in non-CRF expressing (non-GFP expressing) cells of the PVN in virus injected floxed GRF1 mice (Fig. 4, black bars).

Similar to PVN injection of adeno-CRE virus (Fig. 2), injection of CRF-CRE virus into EA female floxed GRF1 knockout mice led to a $\sim 50 \%$ decrease in CORT response immediately after the 7th exposures to restraint stress, compared to their GFP injected counterparts (Fig. 5A), a value similar to that observed in whole PVN GRF1 knockout (3-way ANOVA (factors: sex/age, CRE, 7DS) revealed a significant effect for sex/age $\left(\mathrm{F}_{(2,51)}=11.40, P<0.0001\right)$ and 7DS $\left(\mathrm{F}_{(1,51)}=324.6, P<0.0001\right)$, as well as the interaction between these two factors $\left(\mathrm{F}_{(2,51)}=11.17, P<0.0001\right)$, the interaction between sex/age and CRE $\left(\mathrm{F}_{(2,51)}=4.480\right.$, $P=0.0161)$, and the interaction of all three main factors $\left(\mathrm{F}_{(2,51)}=4.632, P=0.0142\right)$, without a significant interaction between CRE and 7DS $\left(\mathrm{F}_{(1,51)}=3.073, P=0.0856\right)$. Tukey's multiple comparisons post hoc tests revealed a significant decrease in CORT levels after 7DS between adeno-GFP and adeno-CRE injected early-adolescent females $(q=6.920$, $P=0.0006)$.

Moreover, performing a time course of serum CORT levels after the seventh stress exposure showed a $~ 50 \%$ 


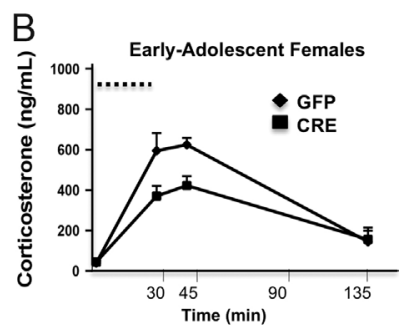

GFP CRH-CRE
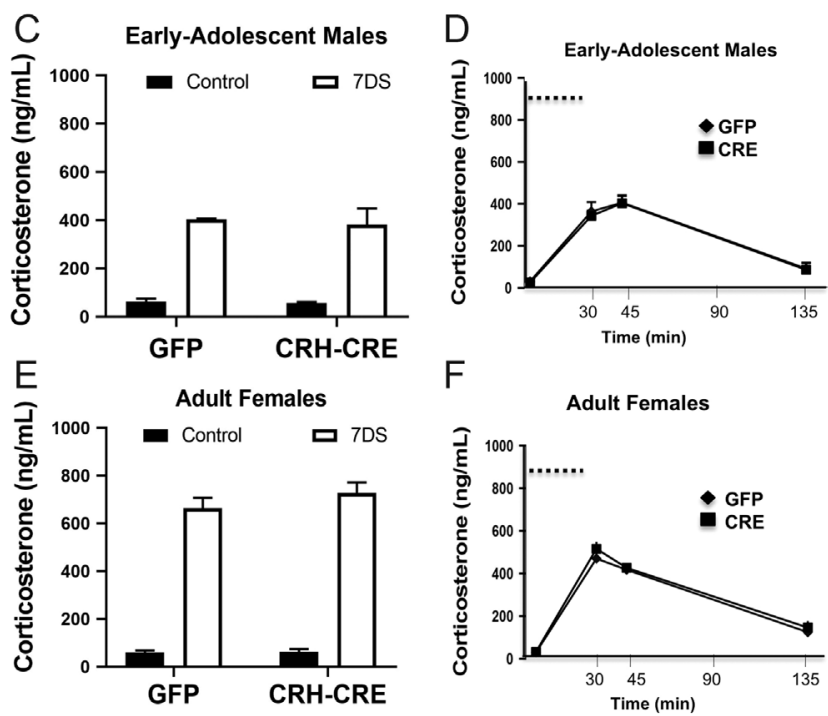

Figure 5

Knockdown of GRF1 expression specifically in CRF cells of the PVN suppresses elevated CORT levels in response to 7DRS in EA females, but not EA males or adult females. (A) Suppression of GRF1 expression in the CRF cells of the PVN of EA females partially blocks elevated serum corticosterone response to seven exposures of restraint stress $(30 \mathrm{~min} /$ day). Serum corticosterone levels measured after stereotactic injection of either CRF-cre expressing lentivirus, or a GFP-expressing virus into the PVN of floxed GRF1 mice followed by control handling or 7DS. $n=4$ mice/ group for both control groups and GFP-injected 7DS EA females, and $n=7$ mice for CRF-Cre injected 7DS EA females. (B) Time course of serum CORT response. Data in $(A)$ is included along with CORT levels measured 15 min and $105 \mathrm{~min}$ following the end of the stressor. $n=3$ mice/group (C).

Suppression of GRF1 expression in the CRF cells of the PVN of EA males does not affect serum CORT response to 7DRS $n=7$ mice/group (D). Time course of serum CORT response. Data in (D) is included along with CORT levels measured 15 min and 105 minutes following the end of the stressor. $n=3$ mice/group (E). Suppression of GRF1 expression in the CRF cells of the PVN of adult females does not affect serum CORT response to 7DRS $n=7$ mice/group (F). Time course of serum CORT response. Data in $(F)$ is included along with CORT levels measured $15 \mathrm{~min}$ and $105 \mathrm{~min}$ following the end of the stressor. $n=3$ mice/group. Data in $(A, C, E)$ analyzed together by three-way ANOVA, data in $(B, D, F)$ analyzed separately using a mixed-effects model. ${ }^{*} * P<0.001$. Dotted line indicates period of restraint stress.

reduction not only $30 \mathrm{~min}$ after beginning of the stress protocol but also $15 \mathrm{~min}$ later (Fig. 5B). Mixed effects model (factors: time, Cre-injection) for EA females revealed a significant effect for time $\left(\mathrm{F}_{(1.319,8.792)}=46.48\right.$,
$P<0.0001)$ with a significant interaction between the two factors $\left(\mathrm{F}_{(3,20)}=3.194, P=0.0457\right)$, the effect of CREinjection was just outside of significance $\left(F_{(1,12)}=4.689\right.$, $P=0.0512)$; Sidak's post hoc multiple comparisons revealed a significant difference between GFP and CRE injected animals immediately after the stress $(\mathrm{t}=4.831, P=0.0116)$, and $15 \mathrm{~min}$ after the stress $(\mathrm{t}=10.05, P=0.0384)$. By 150 min, CORT levels in both control and GRF1-knockdown mice returned to almost normal levels and a significant difference was no longer observable. (Fig. 5B). Sidak's post hoc test did not reveal a significant difference in CORT levels after 7DS between GFP and lenti-CRH-CRE injected animals $(\mathrm{t}=0.2156, P=0.9995)$.

Again, no significant effect was observed in EA males (Fig. 5C and D) or adult females (Fig. 5E and F) immediately after the seventh stress exposure as well as up to $120 \mathrm{~min}$ after initiation of stress. This occurred despite the fact that GRF1 is expressed at similar levels in EA male and EA female CRF cells (Fig. 3). Mixed effects model (factors: time, Cre-injection) for EA males revealed a significant effect for time $\left(\mathrm{F}_{(1.585,9.508)}=64.50, P<0.0001\right)$ without a significant interaction between the two factors $\left(\mathrm{F}_{(3,18)}=0.0384, \quad P=0.9896\right) ;$ Sidak's post hoc multiple comparisons test did not reveal a significant difference between GFP and CRE injected animals before the seventh restraint stress, immediately after the stress, $15 \mathrm{~min}$ after the stress, or 105 min after the stress. Mixed effects model (factors: time, Cre-injection) for adult females revealed a significant effect for time $\left(\mathrm{F}_{(1.756,16.39)}=161.2, P<0.0001\right)$ without a significant interaction between the two factors $\left(\mathrm{F}_{(3,28)}=0.3276, \quad P=0.8054\right) ;$ Sidak's post hoc multiple comparisons test did not reveal a significant difference between GFP and CRE injected adult female animals before the seventh restraint stress, immediately after the stress, 15 min after the stress, or 105 min after the stress.

Thus, GRF1 in EA female CRF cells is required for a full CORT response of the PVN to 7 days of $30 \mathrm{~min} /$ day restraint stress, but not their EA male or adult female counterparts. Furthermore, as seen in total PVN knockdown (Fig. 2), knockdown of GRF1 in CRF cells reduced the CORT response in EA females to levels near that for EA males, suggesting that GRF1 may be functioning in these cells to account for the increased expression of CORT following stress seen in EA females when compared to their male counterparts (Tukey's multiple comparisons post hoc tests revealed a significant difference in CORT levels after 7DS between EA males and EA females injected with GFP $(\mathrm{q}=6.327, P=0.0023)$ (Fig. 5A and $\mathrm{C})$ ). 
Inhibition of GRF1 expression only in PVN CRF cells suppresses the anxiolytic effect of 7 days (30 $\mathrm{min} /$ day) of restraint stress in early-adolescent (EA) female mice

We showed previously that the paradoxical decrease in anxiety observed previously after exposure of adolescent rodents to other types of stressors (Toledo-Rodriguez \& Sandi 2011) also occurs in Bl6 mice exposed to restraint stress (Uzturk et al. 2015). In particular, we showed that $24 \mathrm{~h}$ after 7 days of restraint stress, EA females spend more time than control animals in the open arms of the elevated plus maze. Interestingly, we found that this was not true for their EA Bl6 male mice counterparts. Moreover, this phenotype was blocked in EA female GRF1 knockout mice, consistent with the block in CORT response these mice display (Uzturk et al. 2015). Thus, we exposed EA female mice whose GRF1 expression was inhibited specifically in PVN CRF cells to this test. Even though the CORT inhibition following 7DRS was not complete in these mice (Fig. 5A), anxiolytic behaviors on the EPM were completely suppressed $24 \mathrm{~h}$ after cessation of the stressors (Fig. 6). Two-way ANOVA (factors: 7DRS, CRE-injection) revealed an overall effect for 7DS $\left(\mathrm{F}_{(1,12)}=5.061, P=0.0440\right)$ without a significant interaction between factors $\left(\mathrm{F}_{(1,12)}=2.558, P=0.1357\right)$. Sidak's post hoc multiple comparisons test revealed a significant difference following 7DS only in GFP injected animals $(\mathrm{t}=2.722, P=0.0367)$.

\section{Knockdown of GRF1 in CRF cells in the PVN hypothalamus does not influence the HPA axis response to short-term restraint stress}

We showed previously that the loss of GRF1 specifically in the CA1 hippocampus of EA females is responsible for the super elevated levels of circulating CORT levels observed in them after short-term stress (30 $\mathrm{min} /$ day of restraint for 3 days) (Uzturk et al. 2015). To explain how this can occur if GRF1 is needed in EA female CRF cells to generate a full CORT response, GRF1 was knocked out specifically in CRF cells (as in Fig. 5), and mice were then exposed to only 3 days of restraint stress at the end of the experiment. In this case, the lenti-CRF-CRE virus was also injected into the PVN at pn 21, but restraint stress was initiated 11 rather than 7 days later, so that the mice were exposed to the virus for the same amount of time and the mice were the same age at the end of the experiment as those from 7 days of restraint stress. In contrast to the inhibitory effect observed from similarly injected EA female mice exposed

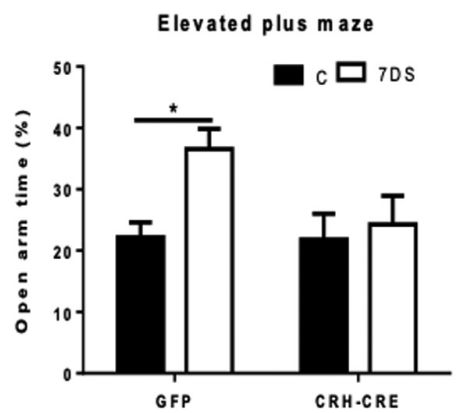

Figure 6

Knockdown of GRF1 expression specifically in CRF cells of the PVN blocks the anxiolytic effects of 7DRS. Following stereotactic injection of either CRF-cre expressing lentivirus or a GFP-expressing virus into the PVN of floxed GRF1 mice, animals were either exposed to 7DRS or control handling. On the following day, they were assayed for time spent in the open arms of the elevated plus maze ( $n=4$ mice/group). Data analyzed by two-way ANOVA. * $P<0.05$.

to 7 days of stress (Fig. 5A), no effect was observed right after only 3 days of restraint stress (Fig. 7A). (2-way ANOVA (factors: CRE, 3DS) revealed a significant effect for 3DS $\left(\mathrm{F}_{(1,12)}=190.3, P<0.0001\right)$ without a significant interaction between factors $\left(\mathrm{F}_{(1,12)}=0.6530, P=0.4348\right)$. Sidak's post hoc multiple comparisons test did not reveal a significant difference between GFP and CRE-injected EA females following 3DS. Additionally, there was no significant difference in CORT levels after 3DS between GFP and lentiCRF-CRE injected animals 15 min following completion of the stressor, or $105 \mathrm{~min}$ following completion of the stressor (Fig. 7B). Mixed effects model (factors: time, Cre-injection) for EA females following 3DS revealed a significant effect for time $\left(\mathrm{F}_{(1.346,8.977)}=130.5, P<0.0001\right)$ without a significant interaction between the two factors $\left(\mathrm{F}_{(3,20)}=0.3149, \quad P=0.8144\right)$; Sidak's post hoc multiple comparisons test did not reveal a significant difference between GFP and CRE injected EA female animals before the third restraint stress, immediately after the stress, 15 min after the stress, or 105 min after the stress.

These findings show that the effects of GRF1 function in EA female CRF cells on HPA axis regulation appear only after additional repeated stress exposures. This implicates GRF1 in a mechanism of PVN CRF cell plasticity that may be specific to EA females, since it is not found in their EA male or adult female counterparts.

\section{Discussion}

The findings reported here show that GRF1 contributes to the HPA axis response to 7 days of restraint stress (30 min/day) (7DRS) in EA females, at least in part, via its function in PVN CRF cells of the hypothalamus. 
A Early-Adolescent Females

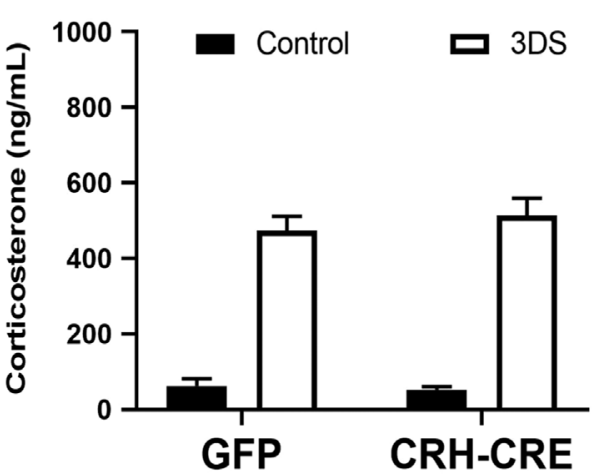

\section{B Early-Adolescent Females}

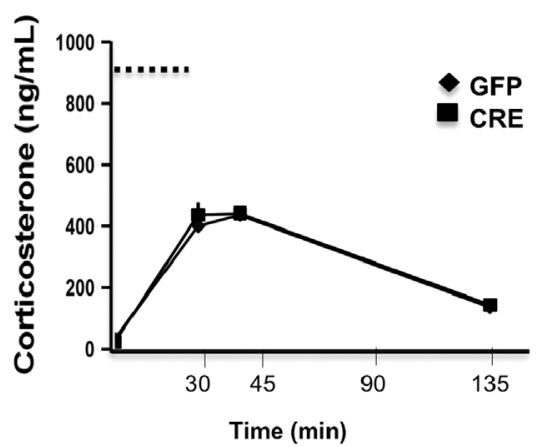

\section{Figure 7}

Knockdown of GRF1 expression specifically in CRF cells of the PVN of EA females does not suppress serum CORT response to 3 days of exposure to restraint stress. After stereotactic injection of either a GFP-expressing or CRF-cre expressing lentivirus into the PVN of floxed GRF1 mice, they were either exposed to 7DRS or control handling. Then serum CORT levels were measured (A). Right after the end of the last stress exposure (B). Time course of serum CORT response. Data in (A) is included along with CORT levels measured $15 \mathrm{~min}$ and $105 \mathrm{~min}$ following the end of the stressor. $n=3$ mice/group. Data in (A) analyzed by two-way ANOVA, and in (B) analyzed by mixed effects model. Dotted line indicates period of restraint stress.

We show that it not only contributes to HPA axis regulated serum CORT levels immediately and 15 min after the last stress exposure, but also decreased anxiety detected $24 \mathrm{~h}$ later. In contrast, GRF1 in CRF cells does not contribute to HPA axis regulation of CORT in EA male or adult female mice. Thus, these results have implications for both sexand age-dependent differences in the stress response. They are also relevant to the process of CRF cell plasticity associated with chronic stress in EA females, since we showed that GRF1 in CRF cells of this population does not contribute to the PVN hypothalamus response to shorterterm restraint stress (3 days of $30 \mathrm{~min} /$ day). Finally, knocking out GRF1 in CRF cells only partially blocked the serum CORT response to stress, while global knockdown of GRF1 led to an almost complete block of this response
(Uzturk et al. 2015). Thus, GRF1 in other brain regions, may also contribute to HPA axis regulation.

The idea that CRF cells in EA females are distinct from their EA male and adult female counterparts is not surprising since both adolescents and females are known to respond to stress differently from males and adults (Bale \& Epperson 2015). In particular, women are more likely than men to suffer from depression (Bangasser \& Valentino 2014) and PTSD (Nemeroff et al. 1984, Bremner et al. 1997) and respond better to a certain class of antidepressants than others (Kornstein et al. 2000). Sexdependent properties of CRF cells may be involved since isolating preadolescent female, but not male, mice from littermates for $<24 \mathrm{~h}$ increased first spike latency and decreased excitability of CRF neurons (Senst et al. 2016).

In general, females and adolescents tend to generate enhanced CORT responses to stress. We observed sex dependence here comparing male and female EA mice after 7DRS (compare Figs 2B, C and 4B, C). Interestingly, GRF1 knockdown in CRF cells of EA females reduced their CORT response to levels similar to those observed in EA males, implying that GRF1 function specifically in EA females contributes to the enhanced HPA axis observed in these animals.

Interestingly, adolescent rats exposed to psychogenic stress, involving 3 days of exposure to a variety of stressors, display what appears to be a paradoxical effect of decreased anxiety associated with increased risk taking (Toledo-Rodriguez \& Sandi 2011). We previously observed a similar anxiolytic effect, increased time in the open arms of the EPM after exposure of EA female Bl6 mice to the repeated restraint stress paradigm studied here. In contrast to studies in rats, we did not observe this effect in EA males (Uzturk et al. 2015). Consistent with inhibition of elevated serum CORT levels in EA female animal wide GRF1 knockout mice, this anxiolytic effect of repeated restraint stress was also completely blocked in these mice. Here, we also observed a complete blockade of the anxiolytic effect of this stressor when GRF1 expression was blocked only in CRF cells, even though it only partially blocked stress-induced elevation of CORT levels to those found in males. Thus, it is possible that GRF1 contributes to other functions ascribed to CRF cells such as those mediated by glutamate efferents to the lateral hypothalamus (Fuzesi et al. 2016). Whatever the mechanism, GRF1 in PVN CRF cells may play a role in stress-induced risk taking, a behavior linked to dangerous outcomes, specifically in adolescent females. Finally, that GRF1 is present in EA male CRF cells implies it plays a different role in them that remains to be determined. 
EA in mice (pn 21-35), the period where GRF1 functions to control the HPA axis in female CRF cells, is thought to be similar to human ages of 10-14 (Burke and Miczek 2014). It is a period of rapid brain development and high vulnerability to excessive stress (Andersen et al. 2008). Risk of depression upon early stress experiences was shown to be highest around early-adolescence and decreases as humans age through mid- and lateadolescence (Andersen \& Teicher 2008). Moreover, EA girls are more prone than their male counterparts to anxiety, depression and eating disorders, as well as suicidal ideation (Hankin et al. 1998, Skogli et al. 2013). Thus, dysregulation of GRF1 function could contribute to these age-related maladies.

Some of these studies have demonstrated that age and sex differences in the HPA axis can arise from the influence of gonadal hormones in adulthood or post pubertal periods (Handa \& Weiser 2014). However, we showed that GRF1 participates in HPA axis function before puberty and ovariectomy has no effect on this role (Uzturk et al. 2015). Thus, in this case, the sex bias of GRF1 function likely results from perinatal testosterone surges in males that makes them independent of GRF1 or from other sex chromosomal effects, which are much less well studied in the context of the stress response (Arnold 2009). We cannot discount the possibility that specific GRF1 function is also present in females younger than EA because we have avoided restraining mice before weaning.

Another key finding of this study is that although knockdown of GRF1 function in CRF cells suppresses HPA axis function after seven exposures to restraint stress, it has no effect after only three exposures. This finding explains how we could have found enhanced CORT response after three restraint stress exposures in our previous animal wide GRF1-knockout studies (Uzturk et al. 2015), since we now know GRF1 is only needed in CRF cells after additional stress exposures. This implies that the requirement for GRF1 in CRF cells for a full response to stress only after seven exposures is part of a form of CRF cell plasticity that is distinct in EA females. CRF cell plasticity has been well documented at the level of altered cell excitability (Maguire 2014, Bains et al. 2015) after various stress paradigms, but sex- and age-specific forms have not. Disturbed plasticity is likely involved in some forms of stress-related disorders, and this form that incorporates GRF1 function could be particularly relevant to those that arise in young women (Maguire 2014, Bains et al. 2015).

That GRF1 function would be an important feature of CRF cells only before puberty in females, and only after repeated stress was surprising because we showed previously that GRF1 contributes to synaptic plasticity, learning, and memory in both sexes, as well as in both adolescents and adults (Li et al. 2006, Jin et al. 2013). Moreover, we documented here that GRF1 is present at similar levels in CRF cells from stressed EA females, and EA males, even though it is only needed for a full HPA axis response in the former. Interestingly, we have observed in a previous study that although GRF1 is present in the hippocampus of 1-month-old mice, it does not begin to contribute to the process of LTP induced by calcium permeable AMPA receptors and contextual discrimination until mice reach 2 months of age (Jin et al. 2013). Thus, what remains to be discovered is not only which GRF1mediated signaling cascades participate in EA female CRF cells to generate proper HPA axis control, but also what is different about repeatedly stressed EA female CRF cells that GRF1 is required in them, but not their EA male or adult female counterparts.

Plasticity of CRF cells to repeated stress has been shown to involve changes in excitability that makes the system more sensitive via stress-induced changes in excitatory/inhibitory input ratio (Maguire 2014, Bains et al. 2015). GRF1 mediates the actions of both excitatory NR2B type NMDA and calcium-permeable type AMPA glutamate receptors involved in synaptic plasticity regulation in the hippocampus. Thus, GRF1 could regulate upstream activation of EA female CRF cells because these cells are also stimulated by glutamate. This mechanism would suggest that a reason for a distinct GRF1-mediated regulation pathway in EA females is to allow them to respond to a distinct set of environmental cues specific to EA females.

Alternatively, EA female-specific GRF1 function could be downstream of cell activation by participating in enhanced CRF gene expression, which is known to occur after stress (Herman \& Tasker 2016). Finally, GRF1 could function in excitation/CRF secretion coupling. For example, a downstream function of GRF1 is to activate the RAS/ERK Map kinase pathway, which is known to promote neurotransmitter secretion through phosphorylation of synaptic regulatory proteins (Chi et al. 2003). This mechanism would imply that the purpose of a distinct GRF1 signaling pathway in EA females is to generate a unique HPA axis response, i.e. more intense, required for this population of animals.

Of course, all of these potential functions for GRF1 in CRF cells would have to be activated in EA females, but not in comparable males or adult females, and only after seven exposures to restraint stress. That means 
that a unique feature(s) of CRFs cells in repeatedly stressed early-adolescent females might be to engage an otherwise inactive GRF1, or alter its signaling specificity to supplement other stimulatory pathways so that the EA female HPA axis response to 7DRS is greater than that we observe in EA males. Alternatively, an EA female-specific GRF1 signaling cascade may participate in 7DRS induced plasticity whose effects are not observed until the end and in this way secure that EA females respond stronger than EA males.

Precedence does exist for sex-dependent specificity differences in how a molecule is used in neuroendocrine signaling cascades. For example, females display a decreased ability of the CRF receptor to associate with $\beta$-arrestin 2 , which biases signaling through Gs-related vs arrestin-related signaling pathways (Valentino et al. 2013).

\section{Declaration of interest}

The authors declare that there is no conflict of interest that could be perceived as prejudicing the impartiality of the research reported.

\section{Funding}

This work was supported by funds to L A F from NIH \# R01MH107536.

\section{Author contribution statement}

Shan-xue Jin and David Dickson helped design and carry out all experiments. Jamie Maguire and Larry Feig helped design experiments. David Dickson and Larry Feig wrote the manuscript.

\section{Acknowledgements}

The authors thank Eric Schmitt, Rockefeller Univ for CRE-inducible 'FLEX' L10a-GFP adeno-associated virus and anti-GFP antibody, and Dong Kong, Tufts University School of Medicine, for the CRF-ires-Cre mice.

\section{References}

Aguilera G \& Liu Y 2012 The molecular physiology of CRH neurons. Frontiers in Neuroendocrinology 33 67-84. (https://doi.org/10.1016/j. yfrne.2011.08.002)

Andersen SL \& Teicher MH 2008 Stress, sensitive periods and maturational events in adolescent depression. Trends in Neurosciences 31 183-191. (https://doi.org/10.1016/j.tins.2008.01.004)

Andersen SL, Tomada A, Vincow ES, Valente E, Polcari A \& Teicher MH 2008 Preliminary evidence for sensitive periods in the effect of childhood sexual abuse on regional brain development. Journal of Neuropsychiatry and Clinical Neurosciences 20 292-301. (https://doi. org/10.1176/jnp.2008.20.3.292)

Arnold AP 2009 The organizational-activational hypothesis as the foundation for a unified theory of sexual differentiation of all mammalian tissues. Hormones and Behavior 55 570-578. (https://doi. org/10.1016/j.yhbeh.2009.03.011)
Bains JS, Wamsteeker Cusulin JI \& Inoue W 2015 Stress-related synaptic plasticity in the hypothalamus. Nature Reviews: Neuroscience 16 377-388. (https://doi.org/10.1038/nrn3881)

Bale TL \& Epperson CN 2015 Sex differences and stress across the lifespan. Nature Neuroscience 18 1413-1420. (https://doi.org/10.1038/ nn.4112)

Bangasser DA \& Valentino RJ 2014 Sex differences in stress-related psychiatric disorders: neurobiological perspectives. Frontiers in Neuroendocrinology 35 303-319. (https://doi.org/10.1016/j. yfrne.2014.03.008)

Blumenthal H, Leen-Feldner EW, Trainor CD, Babson KA \& Bunaciu L 2009 Interactive roles of pubertal timing and peer relations in predicting social anxiety symptoms among youth. Journal of Adolescent Health 44 401-403. (https://doi.org/10.1016/j. jadohealth.2008.08.023)

Blumenthal H, Leen-Feldner EW, Badour CL, Trainor CD \& Babson KA 2014 Pubertal maturation and cortisol level in response to a novel social environment among female adolescents. Journal of Adolescence 37 893-900. (https://doi.org/10.1016/j.adolescence.2014.06.005)

Bremner JD, Licinio J, Darnell A, Krystal JH, Owens MJ, Southwick SM, Nemeroff CB \& Charney DS 1997 Elevated CSF corticotropinreleasing factor concentrations in posttraumatic stress disorder. American Journal of Psychiatry 154 624-629. (https://doi.org/10.1176/ ajp.154.5.624)

Burke AR \& Miczek KA 2014 Stress in adolescence and drugs of abuse in rodent models: role of dopamine, CRF, and HPA axis. Psychopharmacology 231 1557-1580. (https://doi.org/10.1007/s00213013-3369-1)

Cerovic M, Bagetta V, Pendolino V, Ghiglieri V, Fasano S, Morella I, Hardingham N, Heuer A, Papale A, Marchisella F, et al. 2015 Derangement of Ras-guanine nucleotide-releasing factor 1 (Ras-GRF1) and extracellular signal-regulated kinase (ERK) dependent striatal plasticity in L-DOPA-induced dyskinesia. Biological Psychiatry 77 106-115. (https://doi.org/10.1016/j.biopsych.2014.04.002)

Chi P, Greengard P \& Ryan TA 2003 Synaptic vesicle mobilization is regulated by distinct synapsin I phosphorylation pathways at different frequencies. Neuron 38 69-78. (https://doi.org/10.1016/ s0896-6273(03)00151-x)

Darcy MJ, Trouche S, Jin SX \& Feig LA 2014 Age-dependent role for rasGRF1 in the late stages of adult neurogenesis in the dentate gyrus. Hippocampus 24 315-325. (https://doi.org/10.1002/hipo.22225)

Doremus-Fitzwater TL \& Spear LP 2016 Reward-centricity and attenuated aversions: an adolescent phenotype emerging from studies in laboratory animals. Neuroscience and Biobehavioral Reviews 70 121-134. (https://doi.org/10.1016/j.neubiorev.2016.08.015)

Feig LA 2011 Regulation of neuronal function by Ras-GRF exchange factors. Genes and Cancer 2 306-319. (https://doi. org/10.1177/1947601911408077)

Fuzesi T, Daviu N, Wamsteeker Cusulin JI, Bonin RP \& Bains JS 2016 Hypothalamic CRH neurons orchestrate complex behaviours after stress. Nature Communications 7 11937. (https://doi.org/10.1038/ ncomms11937)

Gunnar MR, Talge NM \& Herrera A 2009 Stressor paradigms in developmental studies: what does and does not work to produce mean increases in salivary cortisol. Psychoneuroendocrinology 34 953-967. (https://doi.org/10.1016/j.psyneuen.2009.02.010)

Handa RJ \& Weiser MJ 2014 Gonadal steroid hormones and the hypothalamo-pituitary-adrenal axis. Frontiers in Neuroendocrinology 35 197-220. (https://doi.org/10.1016/j.yfrne.2013.11.001)

Hankin BL, Abramson LY, Moffitt TE, Silva PA, McGee R \& Angell KE 1998 Development of depression from preadolescence to young adulthood: emerging gender differences in a 10-year longitudinal study. Journal of Abnormal Psychology 107 128-140. (https://doi.org/10.1037//0021843x.107.1.128)

Heck AL \& Handa RJ 2019 Sex differences in the hypothalamicpituitary-adrenal axis' response to stress: an important role for https://joe.bioscientifica.com https://doi.org/10.1530/JOE-19-0375
(C) 2020 Society for Endocrinology Published by Bioscientifica Ltd. Printed in Great Britain 
gonadal hormones. Neuropsychopharmacology 44 45-58. (https://doi. org/10.1038/s41386-018-0167-9)

Herman JP \& Tasker JG 2016 Paraventricular hypothalamic mechanisms of chronic stress adaptation. Frontiers in Endocrinology 7 137. (https:// doi.org/10.3389/fendo.2016.00137)

Jin SX, Arai J, Tian X, Kumar-Singh R \& Feig LA 2013 Acquisition of contextual discrimination involves the appearance of a RAS-GRF1/p38 mitogen-activated protein (MAP) kinase-mediated signaling pathway that promotes long term potentiation (LTP). Journal of Biological Chemistry 288 21703-21713. (https://doi.org/10.1074/jbc.M113.471904)

Juraska JM \& Willing J 2017 Pubertal onset as a critical transition for neural development and cognition. Brain Research 1654 87-94. (https://doi.org/10.1016/j.brainres.2016.04.012)

Kornstein SG, Schatzberg AF, Thase ME, Yonkers KA, McCullough JP, Keitner GI, Gelenberg AJ, Davis SM, Harrison WM \& Keller MB 2000 Gender differences in treatment response to sertraline versus imipramine in chronic depression. American Journal of Psychiatry 157 1445-1452. (https://doi.org/10.1176/appi.ajp.157.9.1445)

Krapivinsky G, Krapivinsky L, Manasian Y, Ivanov A, Tyzio R, Pellegrino C, Ben-Ari Y, Clapham DE \& Medina I 2003 The NMDA receptor is coupled to the ERK pathway by a direct interaction between NR2B and RasGRF1. Neuron 40 775-784. (https://doi. org/10.1016/s0896-6273(03)00645-7)

Li S, Tian X, Hartley DM \& Feig LA 2006 Distinct roles for Ras-guanine nucleotide-releasing factor 1 (Ras-GRF1) and Ras-GRF2 in the induction of long-term potentiation and long-term depression. Journal of Neuroscience 26 1721-1729. (https://doi.org/10.1523/ JNEUROSCI.3990-05.2006)

Maguire J 2014 Stress-induced plasticity of GABAergic inhibition. Frontiers in Cellular Neuroscience 8 157. (https://doi.org/10.3389/fncel.2014.00157)

McEwen BS 2007 Physiology and neurobiology of stress and adaptation: central role of the brain. Physiological Reviews 87 873-904. (https:// doi.org/10.1152/physrev.00041.2006)

McLaughlin KA \& King K 2015 Developmental trajectories of anxiety and depression in early adolescence. Journal of Abnormal Child Psychology 43 311-323. (https://doi.org/10.1007/s10802-014-9898-1)

Melon LC, Hooper A, Yang X, Moss SJ \& Maguire J 2018 Inability to suppress the stress-induced activation of the HPA axis during the peripartum period engenders deficits in postpartum behaviors in mice. Psychoneuroendocrinology 90 182-193. (https://doi.org/10.1016/j. psyneuen.2017.12.003)

Nectow AR, Moya MV, Ekstrand MI, Mousa A, McGuire KL, Sferrazza CE, Field BC, Rabinowitz GS, Sawicka K, Liang Y, et al. 2017 Rapid molecular profiling of defined cell types using viral TRAP. Cell Reports 19 655-667. (https://doi.org/10.1016/j.celrep.2017.03.048)

Nemeroff CB, Widerlov E, Bissette G, Walleus H, Karlsson I, Eklund K, Kilts CD, Loosen PT \& Vale W 1984 Elevated concentrations of CSF corticotropin-releasing factor-like immunoreactivity in depressed patients. Science 226 1342-1344. (https://doi.org/10.1126/ science.6334362)
Romanov RA, Zeisel A, Bakker J, Girach F, Hellysaz A, Tomer R, Alpar A, Mulder J, Clotman F, Keimpema E, et al. 2017 Molecular interrogation of hypothalamic organization reveals distinct dopamine neuronal subtypes. Nature Neuroscience 20 176-188. (https://doi.org/10.1038/nn.4462)

Romeo RD 2018 The metamorphosis of adolescent hormonal stress reactivity: a focus on animal models. Frontiers in Neuroendocrinology 49 43-51. (https://doi.org/10.1016/j.yfrne.2017.12.003)

Romeo RD, Bellani R, Karatsoreos IN, Chhua N, Vernov M, Conrad CD \& McEwen BS 2006 Stress history and pubertal development interact to shape hypothalamic-pituitary-adrenal axis plasticity. Endocrinology 147 1664-1674. (https://doi.org/10.1210/en.2005-1432)

Senst L, Baimoukhametova D, Sterley TL \& Bains JS 2016 Sexually dimorphic neuronal responses to social isolation. eLife 5 e18726. (https://doi.org/10.7554/eLife.18726)

Skogli EW, Teicher MH, Andersen PN, Hovik KT \& Oie M 2013 ADHD in girls and boys - gender differences in co-existing symptoms and executive function measures. BMC Psychiatry 13 298. (https://doi. org/10.1186/1471-244X-13-298)

Sorge RE, Martin LJ, Isbester KA, Sotocinal SG, Rosen S, Tuttle AH, Wieskopf JS, Acland EL, Dokova A, Kadoura B, et al. 2014 Olfactory exposure to males, including men, causes stress and related analgesia in rodents. Nature Methods 11 629-632. (https://doi.org/10.1038/ nmeth.2935)

Spear LP 2000 The adolescent brain and age-related behavioral manifestations. Neuroscience and Biobehavioral Reviews 24 417-463. (https://doi.org/10.1016/s0149-7634(00)00014-2)

Stern JE \& Filosa JA 2013 Bidirectional neuro-glial signaling modalities in the hypothalamus: role in neurohumoral regulation. Autonomic Neuroscience: Basic and Clinical 175 51-60. (https://doi.org/10.1016/j. autneu.2012.12.009)

Taniguchi H, He M, Wu P, Kim S, Paik R, Sugino K, Kvitsiani D, Fu Y, Lu J, Lin $\mathrm{Y}$, et al. 2011 A resource of Cre driver lines for genetic targeting of GABAergic neurons in cerebral cortex. Neuron 71 995-1013. (https:// doi.org/10.1016/j.neuron.2011.07.026)

Toledo-Rodriguez M \& Sandi C 2011 Stress during adolescence increases novelty seeking and risk-taking behavior in male and female rats. Frontiers in Behavioral Neuroscience 5 17. (https://doi.org/10.3389/ fnbeh.2011.00017)

Uzturk BG, Jin SX, Rubin B, Bartolome C \& Feig LA 2015 RasGRF1 regulates the hypothalamic-pituitary-adrenal axis specifically in earlyadolescent female mice. Journal of Endocrinology 227 1-12. (https:// doi.org/10.1530/JOE-15-0304)

Valentino RJ, Van Bockstaele E \& Bangasser D 2013 Sex-specific cell signaling: the corticotropin-releasing factor receptor model. Trends in Pharmacological Sciences 34 437-444.

Wille-Bille A, Ferreyra A, Sciangula M, Chiner F, Nizhnikov ME \& Pautassi RM 2017 Restraint stress enhances alcohol intake in adolescent female rats but reduces alcohol intake in adolescent male and adult female rats. Behavioural Brain Research 332 269-279. (https://doi.org/10.1016/j.bbr.2017.06.004)

Received in final form 24 March 2020

Accepted 2 April 2020

Accepted Manuscript published online 2 April 2020 https://joe.bioscientifica.com https://doi.org/10.1530/JOE-19-0375 (c) 2020 Society for Endocrinology Published by Bioscientifica Ltd. Printed in Great Britain 